\title{
Evaluation of knowledge of breastfeeding mothers before and after the maternity school
}

\author{
Natalia A. Belyaeva, O.S. Panina, luri V. Chernenkov
}

Saratov State Medical University n.a. V.I. Razumovsky, Saratov, Russia

Accepted 25 September 2014

Original Text (C) Belyaeva N.A., Panina O.S., Chernenkov Yu.V., 2014, published in Saratov Journal of Medical Scientific Research $2014 ; 10(1)$ : $108-110$.

Abstract: Objective - To evaluate the level of knowledge of surveyed women about breastfeeding before and after the maternity school. Material and methods - The anonymous survey of 300 women on breastfeeding has been conducted. The questionnaire consisted of two parts: theoretical and practical. The questionnaire has been filled in on the $3^{\mathrm{d}}$ day after the childbirth (before the maternity course). On the $4^{\text {th }}$ day after the childbirth mothers have been provided with the main issues on breastfeeding and practical recommendations.

Results - The questionnaire survey has showed the low level of knowledge of mothers about breastfeeding before the maternity school. The level of knowledge after the school has increased in 2.5 times. The knowledge in practical aspects has increased in 5.2 times. Conclusion - The courses on breastfeeding contribute to the educational status of mothers concerning the questions of correct lactation dominant.

Keywords: newborn, breastfeeding, educational maternity school, survey

Cite as Belyaeva NA, Panina OS, Chernenkov YuV. Evaluation of knowledge of breastfeeding mothers before and after the maternity school. Russian Open Medical Journal 2014; 3: 0403.

Correspondence to Natalia A. Belyaeva. Phone: +79179837569. E-mail: beliaev_ap@bk.ru

\section{Introduction}

More and more discoveries confirm a great virtue of human milk and breast feeding still even in the group of premature newborn children, not many people today stick up the principle "breast feeding is the best one". Though, even proper slogans do not replace an action. We urge everyone, wherever they are, to mobilize their services for pursuing this goal, demonstrating the superiority of breast feeding as for newborns as for nursing mothers. Life displays that midwives, nurses, doctors, administration of obstetric facilities and other who are responsible for mother and child health, are very seldom skilled to help mothers and newborns with breastfeeding. And overall, many of medical staff are not well informed about the good of breastfeeding and do not give due consideration to it [1-3].

Meanwhile, breastfeeding is essential and, what is the most important, cheap component in reducing child mortality and morbidity of infants. Well-balanced proportion of nutrients and enzymes, immunological substances content necessary for organism activity protection, and epidemic growth factors containing in breast milk, and natural regulating of its composition for adaptation to a newborn's needs - all these are unique [2-4]. Human-milk-fed newborns are 2.5 times less exposed to diseases, and 25 times reduced probability of dying from diarrheic syndrome in the first 6 months of life (comparing with newborns fed with imitation milk). Regular physical contacts of breastfeeding make newborns feel protected and warm, and interaction between a mother and a child promotes emotional and social developing of a child. Breastfeeding also develops maternal instinct and promotes successful moving from pregnancy to lyingin. Postpartum hemorrhage is minimized; breastfeeding is accompanied by uterus involution stimulated by released oxytocin $[2,5]$. Loss of these advantages because of the reducing of frequency and duration of breastfeeding from the 1970s worries everyone who cares about children survivability. Recent years much attention is paid to work with pregnant women and nursing mothers, as the correct formation of breastfeeding dominance is a formula of child's health [2,3].

Aim: estimation by the questionnaire survey of the women's knowledge about breastfeeding before and after maternity school.

\section{Material and Methods}

Saratov Perinatal Center-based anonymous survey asked 300 women about breastfeeding. The questionnaire consisted of two parts: practical and theoretical, women filled the survey on the third day after delivery (before maternity school); after analyzing the data, there had been the maternity school for mothers organized on the 4th day after delivery, where the main items of breastfeeding were explained in details, and practical recommendations about breastfeeding were given, according the revealed mistakes after which women had filled the blanks again.

Statistical analysis was done by follow programs: Statistica 7.0 and Microsoft Excel 2007. To estimate the significance value level of the results ( $p$ ) in different groups there had been used Student's t-test and Mann-Whitney U-test. Critical significance value level at testing statistical hypothesis was accepted at $p<0.05$.

\section{Results}

The survey displayed that the moat part of the 300 of respondents were multiparous women $-57.0 \%$, primiparous 
women $-43.0 \%$. An average age of primiparas was $19-25$ years (54.1\%), multiparous women 31-35 лет (58.0\%). An educational level was the following: $61.0 \%$ of multiparous women had a secondary education, a higher education - 39.0\%; $45.9 \%$ of primiparous women were with a secondary education, $54.1 \%$ were with a higher education. The most of the respondents were from a countryside $(62.5 \%)$, citizens $-37.5 \%$, this can be explained by the fact that many women from the district regions come to Saratov to visit doctors. After analyzing of the theoretical part of the survey there had been revealed that $62.0 \%$ of the respondents do not see any difference between imitation milk and natural breastfeeding, $38 \%$ of the respondents were sure that ingredients of human milk did not differ from cow milk. Women chose one correct variant from the four about advantages of natural breastfeeding in $55.0 \%$ of the cases - about every second variant. Only $18.0 \%$ of the women prefer ask medical specialist about breastfeeding if needed, and $42.0 \%$ of the respondents were sure that it would be better to ask for help their relatives (mother, sister, etc.), other $40.0 \%$ said that they could find the answers in the Internet.

Analyzing of the theoretical part of the survey after the maternity school (lections and practical lessons according the data of the first survey) displayed that knowledge of the women about breastfeeding had increased. So, almost all of the women answered the question about breastfeeding correctly $(94.0 \%$, what is practically by $30.0 \%$ more than before the maternity school) $(p<0.01)$. The great good of breast milk for a baby was noticed by $98 \%$ of the mothers (what is practically by $30.0 \%$ more than before the maternity school $(p<0.01))$. After the maternity school almost all of the women realized that they would ask specialists for helppediatrists, lactation consultant.

\section{Discussion}

The performed survey shows a low level of women's knowledge about breastfeeding before the maternity school, poorly informed multiparous and primiparous women. Analysis of the questionnaires before the maternity school revealed low level of credibility to medical specialists in breastfeeding questions. Theoretical knowledge about breastfeeding after the maternity school increased by 2.5 times, in some of practical knowledge -5.2 times.

\section{Conclusion}

Lack of information of women about breastfeeding can lead to worsening of the quality of life at mothers and babies, to babies' diseases and reducing of a mother's health parameters. The maternity school is economic and easy to organize method of increasing the level of women's knowledge in breastfeeding and formation of a correct dominance of lactation.

Conflict of interests: none declared.

\section{References}

1. Abolyan IV. Breastfeeding awareness about the basic principles of breastfeeding: the role of medical institutions in the hygienic training of women. Disease prevention and health promotion 1998: 22-25. Russian

2. Abolyan LV. Medical organizational model of protection and support of breastfeeding in the Russian Federation. In: Questions of a modern pediatry: Abstracts of the $X$ Russian pediatric conference. Moscow, Russia, 2005: 631. Russian
3. Vorontsov IM, Fateeva EM. Natural breastfeeding, its value and approval. St. Petersburg, 1998: 272. Russian

4. Global strategy for infant and young children feeding. The $54^{\text {th }}$ session of the World Health Assembly, April 2001: document A54/7. Russian

5. Global Strategy for Infant and Young Child Feeding. Translated from English. Geneva, Switzerland: WHO, 2003. Russian

6. Furtsev VI, Prahin El, Gritsan Al, Budnikova EV. Changes of pediatric health care service politic about practice of breast feeding. Pediatrics 2002; (1): 69-71. Russian

\section{Authors:}

Natalia A. Belyaeva - MD, Postgraduate, Department of Hospital Pediatrics and Neonatology, Saratov State Medical University n.a. V.I. Razumovsky, Saratov, Russia;

O.S. Panina - MD, PhD, Assistant Professor, Saratov Department of Hospital Pediatrics and Neonatology, Saratov State Medical University n.a. V.I. Razumovsky, Saratov, Russia;

luri V. Chernenkov - MD, DSc, Professor, Head of Department of Hospital Pediatrics and Neonatology, Saratov State Medical University n.a. V.I. Razumovsky, Saratov, Russia. 